\title{
Pre-and postoperative cerebral blood flow changes in patients with idiopathic normal pressure hydrocephalus measured by computed tomography (CT)-perfusion
}

\author{
Doerthe Ziegelitz ${ }^{1 *}$, Jonathan Arvidsson ${ }^{2}$, Per Hellström³ ${ }^{3}$ Mats Tullberg ${ }^{3}$, Carsten Wikkelsö ${ }^{3}$, Göran Starck ${ }^{2}$ \\ From Hydrocephalus 2015 \\ Banff, Canada. 18-21 September 2015
}

\section{Introduction}

Computed tomography perfusion (CTP) is an established technique, but has not yet been applied to idiopathic normal pressure hydrocephalus (iNPH), in which cerebral blood flow (CBF) is of pathophysiological, diagnostic and prognostic interest. The aim of this work was to determine the pre-and postoperative regional and global CBF in iNPH by CTP, expecting the results to confirm the findings of a perfusion evaluation on the same group of patients and controls, previously performed with magnetic resonance perfusion (MRP).

\section{Methods}

CTP was performed in 18 iNPH patients pre- and 3 months postoperatively. One postoperative CTP was omitted from the analysis because of a confounding subdural hematoma. 6 healthy, age-matched individuals (HI) served as controls at baseline. The CTP covered 4 adjacent $5 \mathrm{~mm}$ sections immediately above the posterior commissure. CBF was calculated in 12 cortical and subcortical regions of interest. Besides group comparison of the CBF estimates and examination of individual, postoperative CBF changes, also the correlation of CBF and the severity of symptoms was analyzed. Probable iNPH was diagnosed based on the iNPH Guidelines and clinical performance was assessed according to a newly developed iNPH scale.

\footnotetext{
* Correspondence: doerthe.ziegelitz@vgregion.se

'Neuroradiology, Clinical Sciences, Sahlgrenska Academy at University of Gothenburg, Sweden

Full list of author information is available at the end of the article
}

\section{Results}

The preoperative CBF in iNPH patients was significantly reduced in the normal appearing and periventricular white matter (PVWM), the lentiform nucleus and the global parenchyma. No CBF differences were found between responders and non-responders. After shunt diversion CBF increased in responders in all anatomical regions by $2.5-32 \%$ to the perfusion level of $\mathrm{HI}$, but remained significantly reduced in the PVWM of non-responders. The pre-and postoperative $\mathrm{CBF}$ of cortical and subcortical regions correlated with the intensity of symptoms and the total iNPH scale score.

\section{Conclusions}

In spite of limited spatial coverage, CTP can measure CBF changes in iNPH. CTP confirmed largely previous MRP-based results, indicating the reliability of both perfusion methods.

\section{Authors' details \\ ${ }^{1}$ Neuroradiology, Clinical Sciences, Sahlgrenska Academy at University of Gothenburg, Sweden. ${ }^{2}$ Radiation Physics, Clinical Sciences, Sahlgrenska Academy at University of Gothenburg, Sweden. ${ }^{3}$ Clinical Neuroscience and Rehabilitation, Neuroscience and Physiology, Sahlgrenska Academy at University of Gothenburg, Sweden.}

Published: 18 September 2015

\section{References}

1. Ziegelitz, et al: Cerebral perfusion measured by dynamicsusceptibility contrast MRI is reduced in patients with idiopathic normal pressure hydrocephalus. J Magn Reson Imaging 2014, 39(6):1533-42.

2. Ziegelitz, et al: In patients with idiopathic normal pressure hydrocephalus postoperative cerebral perfusion changes measured by 
dynamic susceptibility contrast MRI correlate with clinical improvement Submitted and accepted for publication in JCAT 2015.

doi:10.1186/2045-8118-12-S1-P59

Cite this article as: Ziegelitz et al:: Pre-and postoperative cerebral blood

flow changes in patients with idiopathic normal pressure hydrocephalus measured by computed tomography (CT)-perfusion. Fluids and Barriers of the CNS 2015 12(Suppl 1):P59.

Submit your next manuscript to BioMed Central and take full advantage of:

- Convenient online submission

- Thorough peer review

- No space constraints or color figure charges

- Immediate publication on acceptance

- Inclusion in PubMed, CAS, Scopus and Google Scholar

- Research which is freely available for redistribution

Submit your manuscript at www.biomedcentral.com/submit 